\title{
In-Situ Monitoring of the Effect of External Environment on a Contemporary Building in Prague: The Performance of the Additional Thermal Insulation System
}

\author{
Zbyšek Pavlík ${ }^{1}$, Jan Fořt ${ }^{1}$, Robert Černý ${ }^{1}$ \\ ${ }^{1}$ Czech Technical University in Prague, \\ Faculty of Civil Engineering, \\ Thákurova 7, 16629 Prague, Czech Republic
}

\author{
Pavel Beran ${ }^{2}$ \\ ${ }^{2}$ Academy of Sciences of the Czech Republic, \\ Institute of Theoretical and Applied Mechanics, \\ Centre of Excellence Telč / ARCCHIP, \\ Batelovská 485-486, 58856 Telč, Czech Republic
}

\begin{abstract}
Experimental assessment of the hygrothermal performance of an office building in Prague, which was recently provided by an additional contact thermal insulation system (TIS), is done in the paper, in order to evaluate the contribution of the applied TIS to the moderation of the interior climate. At the long-term in-situ analysis of the building, the measurement of relative humidity and temperature profiles along the cross section of a selected part of the building envelope is carried out. The measurement is realised for 1.5 year on the non-insulated wall at first, and after the application of the exterior TIS it continues for another 1 year. The obtained results show an improvement in the hygrothermal function of the analysed building envelope due to the application of TIS that reduces significantly the thermal response of the investigated building to the changes of environmental conditions.
\end{abstract}

Keywords-external environment; in situ monitoring; contact thermal insulation system; polystyrene board; hygrothermal function

\section{INTRODUCTION}

The energy consumption worldwide is increasing due to the increasing population, migration to large cities, and improvement in the standard of living. With the worldwide rise of energy consumption and energy cost in the building sector, the effort to reduce energy consumption for buildings operation and to use renewable energy is a necessity. According to the original work published by Waqas and Din [1], about $30-40 \%$ of the annual world primary energy is consumed by the building sector, which is thus responsible for one third of greenhouse gas emissions, and thereby contributes substantially to the global warming around the world. Although the buildings share of the world total energy consumption is expected to decrease, due to the long-time enhanced demands on quality thermal insulation of buildings that led to the design and development of low energy and passive houses [2], buildings will still account for $20 \%$ of the total energy demand in coming years. Moreover, the energy consumption of ventilation and air conditioning is today still increasing because of the increasing demand on the thermal comfort in buildings.

In particular, the problem of older buildings that must be adapted with respect to the present requirements on high thermal and hygric comfort of building structures must be solved. One of the most important drawbacks of older buildings is low thermal resistance of their envelopes what causes high energy gains in hot year periods, and energy losses in cold year periods. As the external walls of buildings represent approximately $40-90 \%$ of the total weather-exposed surfaces of buildings, improving their thermal performance highly contributes to the reduction of energy consumption, in addition to enhancing the building thermal comfort. Here, the energy consumption for heating and cooling purposes in buildings can be reduced by an appropriate adjustment of building envelope components in terms of thermal, optical and dimensional properties.

For additional thermal insulation of buildings, both exterior and interior TISs are used, respecting their advantages and limitations. In general, the external TISs are more popular because of their indubitable advantage that represents the realization of a complex building enclosure without any problems in ceilings and roof areas. Also, the possible risk of condensation of water vapour coming from the interior is in the exterior TISs limited, especially in the systems with ventilated air gap. The effectiveness of the interior thermal insulation systems is a very often discussed problem, especially due to the possible interstitial condensation, frost damage, salt efflorescence, mould growth and other damage patterns [3]. Nevertheless, in the urban context, where a strict building line often excludes exterior insulation, or in cases of buildings with a historical or worth-preserving facade, interior insulation is often the only possible solution to improve the thermal performance of building enclosure [4], [5]. In that case, the interior insulation systems allow to prevent moisture damages and to upgrade the thermal properties of the envelope as the only reasonable option [6]. The building presented in this work is a typical reinforced concrete column structure, where the application of the exterior contact TIS is a logical solution.

\section{EXPERIMENTAL}

The investigations were done on the administrative building built in 1980s. It is a typical reinforced concrete column structure having 3 stories. The exterior surface is constructed from the hung facade slabs formed of steel frames, aluminous window frames, glass, and insulation boards. Part of the envelope is built from cavity brick blocks on the surface provided by cement-lime plaster. The building is located in the north-west suburb part of Prague, the capital of the Czech Republic.

The additional exterior contact TIS was applied during autumn 2013 (October - December). It consists of adhesive mortar JUB JUBIZOL (polymer-modified micro-reinforced cement mortar mixture) that serves for gluing of insulation 
boards and as a brown coat, expanded polystyrene board EPS PERIMETR having a thickness of $150 \mathrm{~mm}$, alkali resistant reinforcing mesh, acrylic base paint UNIGRUND applied under thin-film plasters, and water vapor permeable siloxane plaster UNISIL $G$ having fungicidal additives. The insulation boards are secured using fixing plastic/metal anchors. The schematic view of the applied TIS is given in Fig. 1.

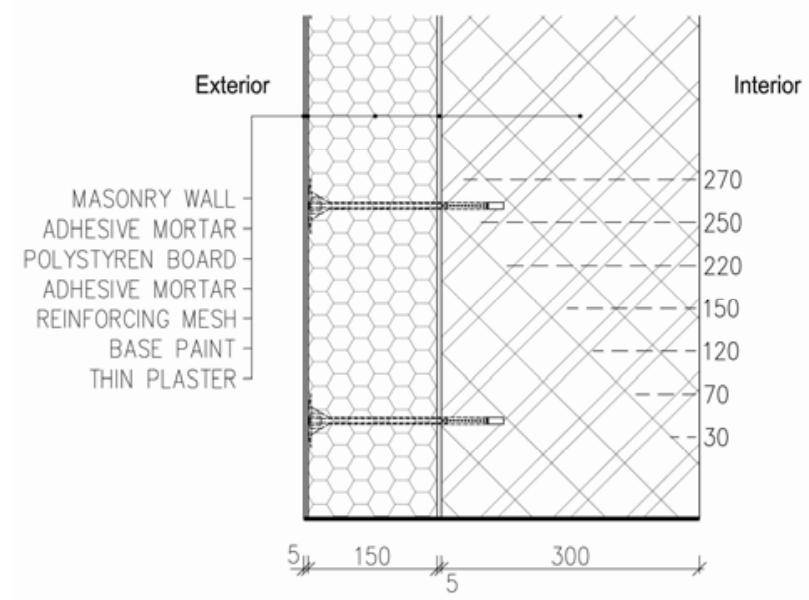

Fig. 1: Schematic description of the additional TIS, sensors installation

The monitoring of the hygrothermal performance was done for the part of the envelope formed by cavity brick blocks and exterior and interior plasters (before application of TIS). This part of building facade is considered to be the main cause of the heat losses of the building. Here, also the material durability problems are expected.

In the tested structure, continuous monitoring of relative humidity and temperature was done. For that purpose, the combined mini-sensors produced by Ahlborn (Germany), were used. The capacitance relative humidity sensors are applicable in the range of humidities of 5-98\% with the accuracy within $\pm 2 \%$, the resistance temperature sensors have the accuracy of $\pm 0.4{ }^{\circ} \mathrm{C}$ in the temperature range of 20 to $0{ }^{\circ} \mathrm{C}$ and $\pm 0.1{ }^{\circ} \mathrm{C}$ in range of $0-70{ }^{\circ} \mathrm{C}$. The particular sensors were connected with the measuring unit that was controlled by computer. The data were continuously collected, whereas the experiment was operated by a remote computer station. In total, 16 measuring channels were installed. The measurement started in April 2012 and still continues.

Together with the monitoring of temperature and relative humidity profiles, the measurement of climatic conditions of the researched building was done using the weather station Fiedler-Mágr (Czech Republic). The apparatus includes a universal telemetric unit M4016 that controls weather station and stores the measured data. It is equipped with 16 recording channels. To the main station unit, there are connected the following sensors: W2t for the measurement of wind velocity and direction (heated version), RV12 for the relative humidity and temperature measurement, psychrometer SR02 with a collecting board of $200 \mathrm{~cm} 2$ and with the distinction of waterfalls of $0.2 \mathrm{~mm}$, and pyranometer for the measurement of global solar radiation. The weather station was placed on the roof of the studied building.

\section{RESULTS AND DISCUSSION}

The exterior climatic conditions measured in 2013 are given in Figs. 2, 3

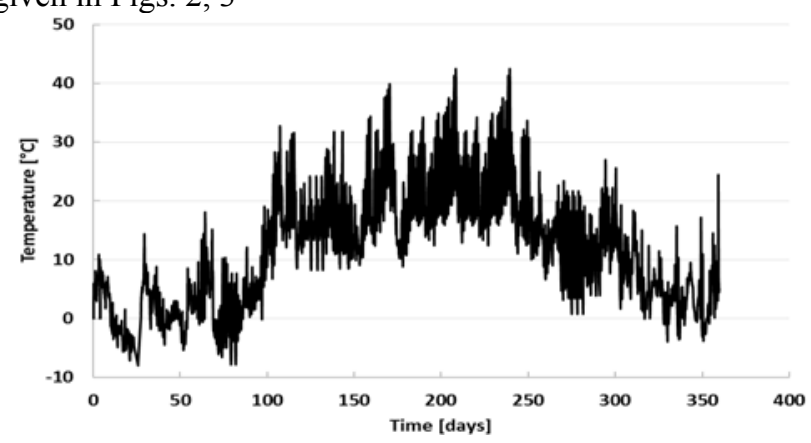

Fig. 2: Exterior temperature in 2013

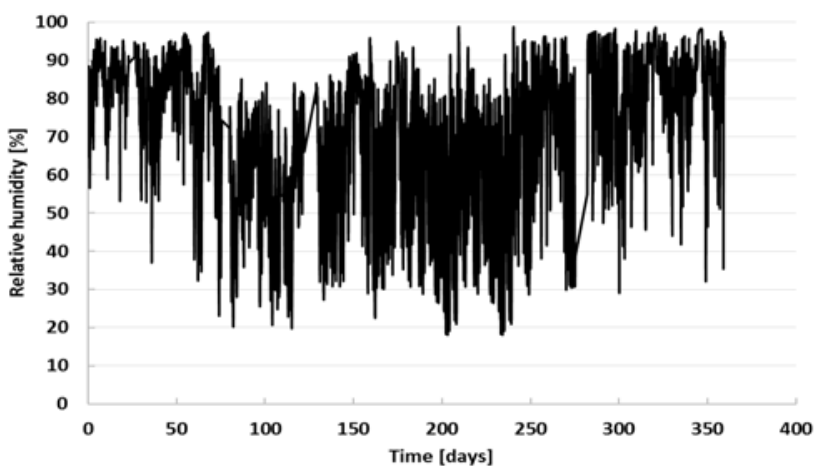

Fig. 3: Exterior relative humidity in 2013

Here, hourly values of meteorological data are presented. Similar data can be anticipated for other years of building investigation. The winter temperature varied between $-8{ }^{\circ} \mathrm{C}$ and $14{ }^{\circ} \mathrm{C}$. In summer, the temperature variation between $9{ }^{\circ} \mathrm{C}$ and $42{ }^{\circ} \mathrm{C}$ was observed. The relative humidity varied from $18 \%$ to $98 \%$, whereas this data was not affected by the temperature of particular year period only, but also by the amount of rainfall.

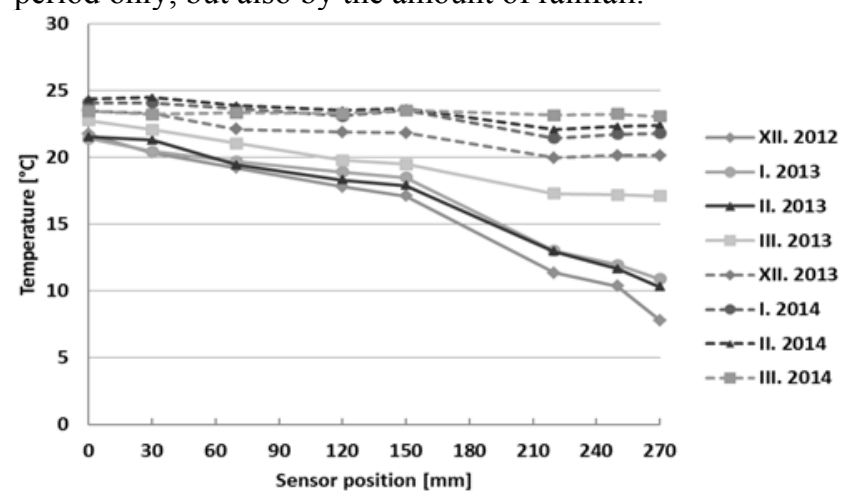

Fig. 4: Temperature profiles measured in the studied building envelope winter 


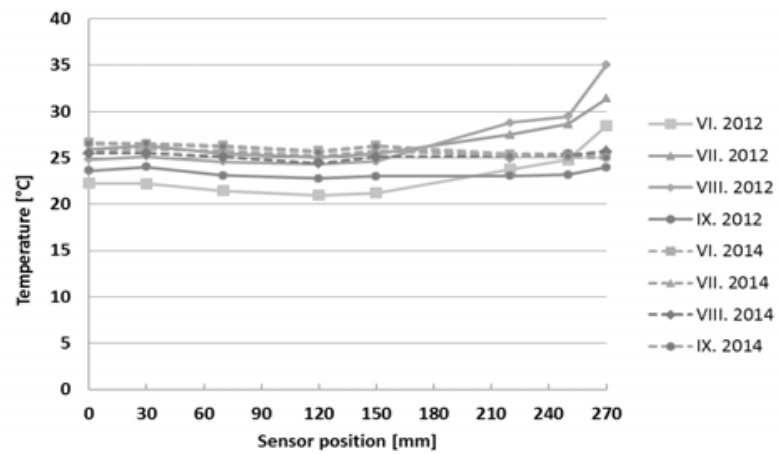

Fig. 5: Temperature profiles measured in the studied building envelopesummer

Temperature profiles measured during the winter and summer period of the particular monitored years are given in Figs. 4, 5. One can see a visible effect of the additional application of the exterior TIS on the thermal performance of the researched building envelope. Before the realization of TIS, the temperature in cavity brick wall varied from approx. $20{ }^{\circ} \mathrm{C}$ to approx. $7^{\circ} \mathrm{C}$ what was risky from the point of view of possible water vapour condensation and other related degradation problems. The application of TIS led to the increase of temperature in the original structure that was above $20{ }^{\circ} \mathrm{C}$.

Looking at the data measured for the summer period, one can see that TIS decreased the temperature variation in the original brick wall. On the other hand, the interior temperature remained high, which can be assigned to the heat solar gains through the hung façade system. Thus, for the optimal conditions of building occupants, the air conditioning is recommended in hot summer days. In Fig. 6, there are presented temperature daytime variations corresponding to January 1 . One can observe noticeable changes of the temperature values measured in the exterior part of the tested wall during the day and night before application of TIS. The realization of TIS significantly reduced the effect of exterior temperature changes on the temperature response of the studied envelope what is beneficial from the point of view of energy consumption for building conditioning.

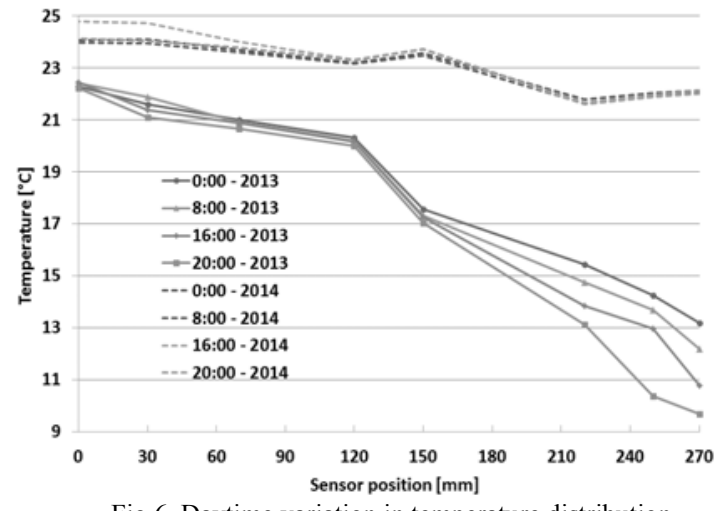

Fig.6. Daytime variation in temperature distribution
The application of TIS had no significant influence on the distribution of relative humidity in the researched structure, as well as in the room interior. The measured relative humidity of the interior air was typically very low, about $25 \%$. The highest values of relative humidity were measured in winter periods, and were located in the distance of $270 \mathrm{~mm}$ from the interior surface. Nevertheless, these values were still lower than $50 \%$.

\section{CONCLUSIONS}

An in situ evaluation of the functionality of additionally applied exterior contact TIS confirmed its benefits for the thermal performance of the studied building. Especially in the cold period of the year, the applied TIS reduced the effect of the exterior temperature changes and led to a significant increase of temperature in the original structure that remained above $20^{\circ} \mathrm{C}$. Thus, the risk of potential water vapor condensation was eliminated.

\section{ACKNOWLEDGEMENT}

This work has been supported by the Czech Science Foundation, under project No P105/12/G059.

\section{REFERENCES}

[1] Waqas, A. \& Din, Z.U., Phase change material (PCM) storage for free cooling of buildings-A review. Renewable and Sustainable Energy Reviews, 18, pp. 607-625, 2013.

[2] Pavlík, Z., Trník, A., Keppert, M., Pavlíková, M., Žumár, J. \& Černý, R., Experimental Investigation of the Properties of Lime-Based Plaster-Containing PCM for Enhancing the Heat-Storage Capacity of Building Envelopes. International Journal of Thermophysics, 35, pp. 767-782, 2014.

[3] Kolaitis, D.I., Malliotakis, E., Kontogeorgos, D.A., Mandilaris, I., Katsourinis, D.I. \& Founti, M.A., Comparative assessment of internal and external thermal insulation systems for energy efficient retrofitting of residential buildings. Energy and Buildings, 64, pp. 123-131, 2013.

[4] Vereecken, E. \& Roels, S., A comparison of the hygric performance of interior insulation systems: A hot box-cold box experiment. Energy and Buildings, 80, pp. 37-44, 2014.

[5] Pavlík, Z., Jirickova, M., Pavlík, J., Černý, R., Interior Thermal Insulation System Based on Hydrophilic Mineral Wool. Journal of Building Physics, 29, pp. 21-35, 2005.

[6] Pavlík, Z. \& Černý, R., Experimental Assessment of Hygrothermal Performance of an Interior Thermal Insulation System Using a Laboratory Technique Simulating On-Site Conditions. Energy and Buildings, 40, pp. 673-678, 2008. 